\title{
Thermal niche of Atlantic cod Gadus morhua: limits, tolerance and optima
}

\author{
David A. Righton ${ }^{1, *}$, Ken Haste Andersen ${ }^{2}$, Francis Neat ${ }^{3}$, Vilhjalmur Thorsteinsson ${ }^{4}$, \\ Petur Steingrund ${ }^{5}$, Henrik Svedäng ${ }^{6}$, Kathrine Michalsen ${ }^{7}$, Hans-Harald Hinrichsen ${ }^{8}$, \\ Victoria Bendall ${ }^{1}$, Stefan Neuenfeldt ${ }^{2}$, Peter Wright ${ }^{3}$, Patrik Jonsson ${ }^{6}$, Geir Huse ${ }^{7}$, \\ Jeroen van der Kooij ${ }^{1}$, Henrik Mosegaard ${ }^{2}$, Karin Hüssy ${ }^{2}$, Julian Metcalfe ${ }^{1}$
}

${ }^{1}$ Centre for Environment, Fisheries and Aquaculture Science (CEFAS), Lowestoft NR33 0HT, UK ${ }^{2}$ National Institute of Aquatic Resources, Technical University of Denmark, Charlottenlund 2920, Denmark ${ }^{3}$ Marine Scotland:Science, Marine Laboratory, Aberdeen AB11 9DB, UK

${ }^{4}$ Marine Research Institute, 121 Reykjavik, Iceland

${ }^{5}$ Faroe Marine Research Institute, 110 Tórshavn, Faroe Islands

${ }^{6}$ Swedish Board of Fisheries, 40126 Göteborg, Sweden

${ }^{7}$ Institute of Marine Research, 5817 Bergen, Norway

${ }^{8}$ Leibniz Institute of Marine Sciences, 24105 Kiel, Germany

\begin{abstract}
Recent studies in the marine environment have suggested that the limited phenotypic plasticity of cold-adapted species such as Atlantic cod Gadus morhua L. will cause distributions to shift toward the poles in response to rising sea temperatures. Some cod stocks are predicted to collapse, but this remains speculative because almost no information is available on the thermal tolerance of cod in its natural environment. We used electronic tags to measure the thermal experience of 384 adult Atlantic cod from 8 different stocks in the northeast Atlantic. Over 100000 d of data were collected in total. The data demonstrate that cod is an adaptable and tolerant species capable of surviving and growing in a wide range of temperate marine climates. The total thermal niche ranged from -1.5 to $19^{\circ} \mathrm{C}$; this range was narrower $\left(1\right.$ to $\left.8^{\circ} \mathrm{C}\right)$ during the spawning season. Cod in each of the stocks studied had a thermal niche of approximately $12^{\circ} \mathrm{C}$, but latitudinal differences in water temperature meant that cod in the warmer, southern regions experienced 3 times the degree days (DD; $4000 \mathrm{DD} \mathrm{yr}^{-1}$ ) than individuals from northern re-

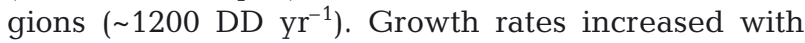
temperature, reaching a maximum in those cod with a mean thermal history of between 8 and $10^{\circ} \mathrm{C}$. Our direct observations of habitat occupation suggest that adult cod will be able to tolerate warming seas, but that climate change will affect cod populations at earlier life-history stages as well as exerting effects on cod prey species.
\end{abstract}

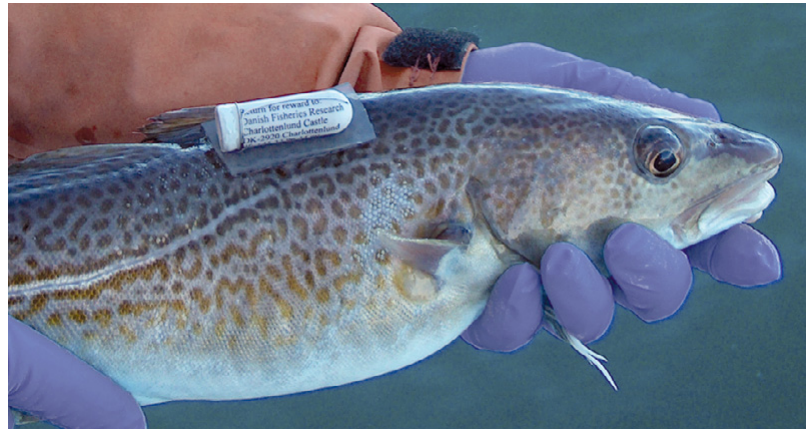

Electronic tags attached to cod give unique insights into how climate change may affect the growth and distribution of this species.

Image: Stefan Neuenfeldt

KEY WORDS: Atlantic cod . Gadus morhua . NE Atlantic - Electronic tag - Climate - Behaviour

Resale or republication not permitted without written consent of the publisher

\section{INTRODUCTION}

Knowledge of the thermal biology of ectothermic animals is fundamental to understanding their ecology and distribution (Brown et al. 2004) and assessing the likelihood of change in population dynamics or geo- 
graphic range that may occur due to climate change (Wikelski \& Cook 2006, Young et al. 2006). Recent studies in the marine environment have suggested that the species distributions may be changing rapidly (Rose 2004, Drinkwater 2005, Perry et al. 2005, Parmesan 2006), but empirical data on the response of marine species to different thermal niches and environments is lacking (Pörtner \& Knust 2007, Donaldson et al. 2008).

Cod Gadus morhua is a widely distributed, commercially important species that used to be found in enormous abundance throughout the shelf ecosystems of the North Atlantic (Hutchings 2004, Rose 2004). Similar to most commercial species, most cod stocks are now heavily over-exploited (Worm et al. 2006, ICES 2007, Pitcher et al. 2009) and, in some cases, collapsing (Hutchings \& Myers 1994, Cook et al. 1997, O'Brien et al. 2000, Christensen et al. 2003, Hutchings 2004, Rose 2004), with continued debate as to whether this is the consequence of high fishing mortality, climate change or a combination of the two. In consequence, there is considerable interest in defining the response of cod to climate, and using this information to predict how this may affect future stock recovery.

Most observations of cod thermal response have been made in the laboratory (Schurmann \& Steffensen 1992, Claireaux et al. 1995). Common to most of these studies is the concept of optimality and, like all similar studies, the optimum depends upon the currency used to define success. Most experimental work has focussed on defining the temperature at which growth rate is maximised (Brander 1995, Claireaux et al. 2000, Pörtner et al. 2001, Björnsson \& Steinarsson 2002, Lannig et al. 2004). The measured optima range between 8 and $15^{\circ} \mathrm{C}$ and depend on size; smaller fish grow faster at higher temperatures, whilst the growth of larger fish is greater at lower temperatures (Jobling 1988, Pörtner et al. 2001, Petersen \& Steffensen 2003, Drinkwater 2005).

Although experimental studies have been useful in finding thermal optima for growth, using this optima as the principal predictor of individual and stock performance under different climate scenarios fails to recognise that individual cod occupy a habitat envelope that is defined by other ecological and physiological drivers, such as food abundance, abundance of conspecifics and habitat type. Furthermore, the performance and resilience of cod stocks will also depend on regional fishing mortality and any particular life-history characteristics of regional stocks, such as growth rate and age at maturity. To determine how individuals and stocks may respond to a warming marine environment, it is as important to define the upper and lower limits of tolerance to temperature as it is to define the thermal optima. This is because these limits provide the boundaries of the thermal habitat (or thermal envelope) that cod can occupy, not simply where growth, under otherwise ideal conditions, would be maximised. Recent experiments have explored the upper limits of cod physiology, and have shown that life-support processes cease to function effectively at around $22^{\circ} \mathrm{C}$ (Lannig et al. 2004, Pörtner \& Knust 2007). Experiments at the lower limit have not been conducted (Boutilier 1998). Determining how these physiological limits are realised in the natural environment, where other ecological drivers impinge upon habitat selection, is an important companion to experimental studies, and is of critical importance for decision makers (Cooke \& O'Connor 2010). However, the thermal habitat that cod can occupy under natural conditions is not well known because direct assessments of temperature experience are rare (Ropert-Coudert \& Wilson 2005, Rice 2006, Neat \& Righton 2007). Instead, researchers have needed to combine data from hydrographic and fishing surveys to infer or model the preferred thermal habitat of cod (Blanchard et al. 2005, Rindorf \& Lewy 2006).

Here we quantify and describe the temperatures and depth experience of wild cod determined by a largescale electronic tagging programme in the northeast (NE) Atlantic. This gives the advantage of direct observation of the thermal niche, and has allowed us to assess the evidence for a preferred temperature range, to define the limits of thermal tolerance and to assess the effects of thermal habitat upon growth.

\section{MATERIALS AND METHODS}

Cod tagging and data collection. We deployed over 3000 electronic data-logging tags on cod (see Table S1 in Supplement 1 at www.int-res.com/articles/suppl/ m420p001_supp.pdf for full details of tag attachment) in the NE Atlantic in 8 geographic areas that form the basis of the historical and existing commercial cod fisheries (Fig. 1; see Table S2 in Supplement 1). The tags were programmed to record depth and temperature at intervals between $1 \mathrm{~min}$ and $6 \mathrm{~h}$, depending on the data storage available, to ensure that tags would record data for more than 12 mo if still at liberty. All tagging was conducted under governmental licence and was in adherence with national regulations on the treatment of experimental animals.

Thermal experience. Datasets $>90 \mathrm{~d}$ in length were collated (Table 1, Fig. S1 in Supplement 1 at www.intres.com/articles/suppl/m420p001_supp.pdf), and the mean and SD of temperature and depth were extracted for each day of data, in addition to the daily temperature range. In addition, the subset of data that had been collected at an interval of $30 \mathrm{~min}$ or less $(83 \%$ of total dataset: $81676 \mathrm{~d}$ ) were used to extract the magnitude and frequency of changes in temperature between temperature recordings. The number of degree days expe- 

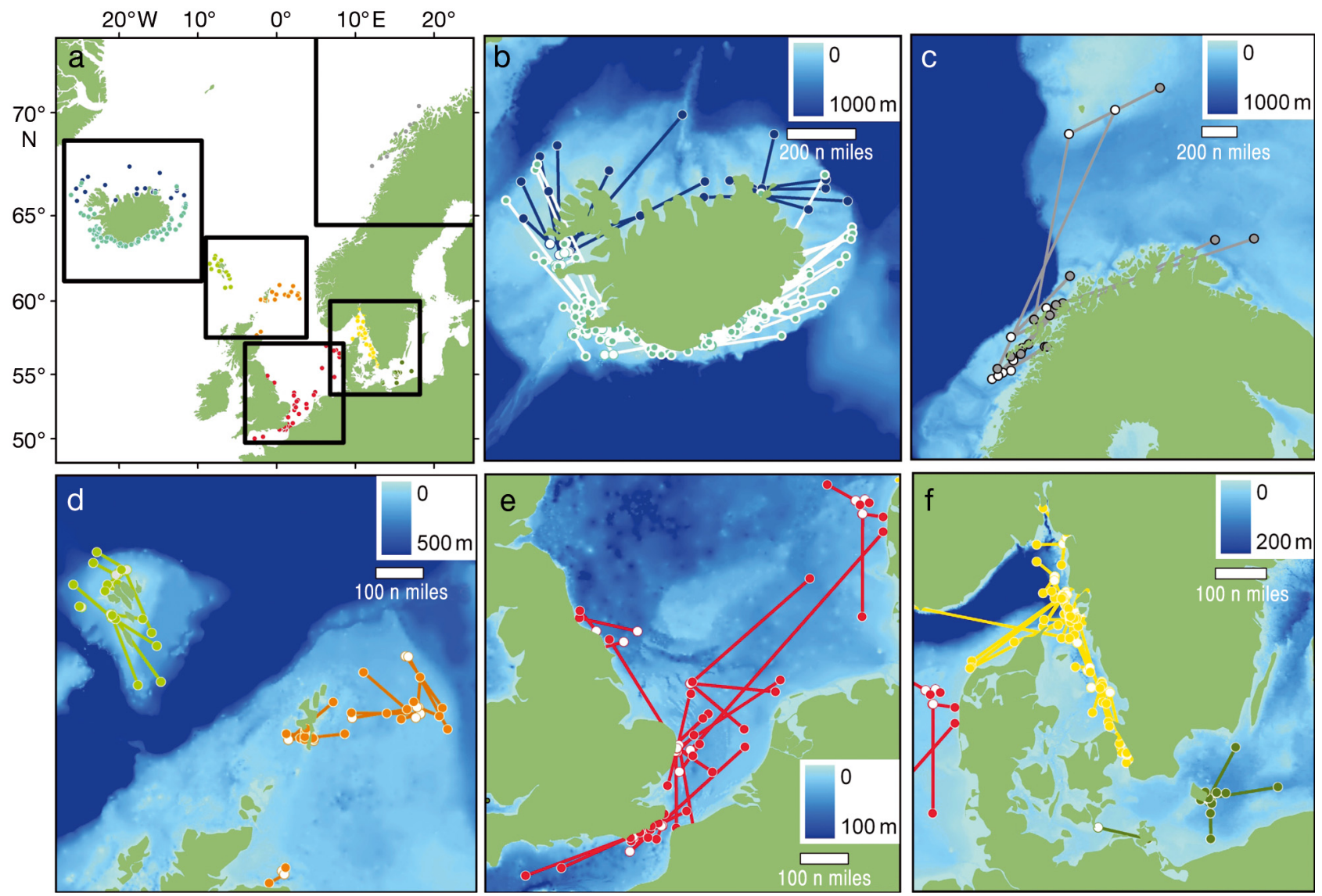

Fig. 1. Area of study and Gadus morhua tagging locations. Tag recapture locations for cod at liberty $>90 \mathrm{~d}$ are shown by solid symbols; release locations are white. Shading of the sea area shows seabed depth. (a) NE Atlantic and boundaries of each map panel: (b) the Icelandic plateau; (c) Barents Sea and Norwegian Shelf (not completely shown in panel a); (d) Faroe Islands and northern North Sea; (e) southern North Sea and English Channel; (f) Skagerrak, Kattegat and Baltic Sea

Table 1. Gadus morhua. Temperature $\left({ }^{\circ} \mathrm{C}\right)$ experienced by cod in each ecosystem. Annual temperature range and spawning temperature range were determined by calculating the difference between values at $10^{-4}$ in the probability density function (pdf) of temperature observations. Daily range values were calculated as the average difference between observed daily maxima and minima recorded by tags in each ecosystem. The maximum range experienced by an individual fish for each ecosystem is also included; values were calculated as the difference between the maximum and minimum values of temperature recorded by the tagged cod. Average degree day values for each ecosystem were calculated as the sum of the average temperature for each day of the year. Values of variance, where presented, represent $1 \mathrm{SD}$. Cod were, on average, at liberty for $251 \pm 172 \mathrm{~d}$ between release and recapture. na: not applicable

\begin{tabular}{|c|c|c|c|c|c|c|c|c|}
\hline Stock & Baltic & Barents & Faroes & N Iceland & SW Iceland & N North Sea & S North Sea & Skagerrak \\
\hline Datasets $>90 \mathrm{~d}$ & 49 & 13 & 17 & 21 & 117 & 36 & 44 & 87 \\
\hline Longest dataset & 608 & 768 & 785 & 1106 & 1246 & 908 & 797 & 512 \\
\hline Total days of data & 9078 & 4582 & 5054 & 8122 & 40299 & 8447 & 8950 & 16131 \\
\hline Mean temperature & $6.23 \pm 2.21$ & $6.40 \pm 2.12$ & $8.28 \pm 1.26$ & $3.61 \pm 1.82$ & $6.51 \pm 2.43$ & $9.19 \pm 1.74$ & $10.65 \pm 3.82$ & $7.19 \pm 2.20$ \\
\hline Spawning temperature & $6.51 \pm 2.11$ & $5.91 \pm 1.11$ & $7.52 \pm 0.50$ & $3.72 \pm 1.08$ & $6.61 \pm 1.52$ & $7.56 \pm 0.48$ & $6.02 \pm 1.09$ & $5.63 \pm 1.34$ \\
\hline Maximum observed & 17.4 & 11.71 & 11.49 & 10.8 & 13.4 & 14.51 & 19.45 & 18.23 \\
\hline Minimum observed & 0.34 & -1.54 & 0.57 & -1.5 & -0.6 & 5.53 & 2.32 & -0.18 \\
\hline Annual range (pdf) & 9.74 & 10.65 & 4.03 & 8.3 & 11.86 & 7.38 & 14.74 & 12.23 \\
\hline Spawning range (pdf) & 9.15 & 5.85 & 3.16 & 6.01 & 7.4 & 4.03 & 6.49 & 7.29 \\
\hline Daily range (average) & $2.06 \pm 1.97$ & $0.77 \pm 0.8$ & $0.39 \pm 0.84$ & $0.98 \pm 1.27$ & $0.69 \pm 0.93$ & $0.27 \pm 0.25$ & $0.37 \pm 0.55$ & $1.42 \pm 1.61$ \\
\hline Average range (liberty) & 10.02 & 6.92 & 3.94 & 6.67 & 7.10 & 4.94 & 8.95 & 9.48 \\
\hline Max. range (lifetime) & 14.99 & 10.22 & 8.54 & 8.45 & 11.8 & 7.96 & 14.78 & 15.96 \\
\hline Degree days (tags $>1 \mathrm{yr}$ ) & 2322 & $2589 \pm 169$ & $3067 \pm 98$ & $1228 \pm 251$ & $2290 \pm 639$ & $3606 \pm 96$ & $3890 \pm 363$ & na \\
\hline Degree days (average) & 2216.8 & 2366.4 & 3024.3 & 1239.5 & 2332 & 3418 & 3974.1 & 2709 \\
\hline Spawning & 809.5 & 368.2 & 682 & 311.8 & 677.9 & 582.5 & 347.9 & 576.2 \\
\hline $\begin{array}{l}\text { Specific growth rate } \\
\left(\mathrm{cm} \mathrm{cm}^{-1} \mathrm{~d}^{-1}\right)\end{array}$ & $0.023 \pm 0.018$ & na & $0.006 \pm 0.005$ & $0.024 \pm 0.018$ & $0.013 \pm 0.011$ & $0.052 \pm 0.022$ & $0.053 \pm 0.033$ & $0.033 \pm 0.028$ \\
\hline
\end{tabular}


rienced by cod at liberty for more than 1 yr was calculated by summing the average temperature recorded for each day of the first year at liberty. The probability density function (pdf) of the thermal experience (using a bin size of $0.5^{\circ} \mathrm{C}$ ) was calculated for cod in each ecosystem on a monthly basis, and the monthly pdfs were averaged to provide a pdf of thermal experience for the full year or for the spawning season. The pdfs for each region were then averaged to calculate an overall pdf for cod in the NE Atlantic, and also for the spawning season (as identified for the Baltic Sea, Wieland et al. 2000; the Barents Sea, Kjesbu et al. 2010; the Faroes, Steingrund \& Gaard 2005; Iceland, Pálsson \& Thorsteinsson 2003; the North Sea, Yoneda \& Wright 2005; and the Skagerrak/Kattegat, Svedäng et al. 2007). The overlap (O) between the thermal conditions cod occupied and the available thermal conditions was calculated as a ratio between the pdf of cod thermal experience and the pdf of available temperatures in the ecosystem (using a bin size of $5^{\circ} \mathrm{C}$ ).

Growth rates. Of the 384 cod that were returned after $90 \mathrm{~d}, 232$ had complete and reliable information on length at release and recapture and a near-complete (to within $2 \mathrm{wk}$ ) record of daily temperature (see Table S3 in Supplement 1). To analyse the relationship between temperature exposure, ecosystem and fish size, a generalised least squares regression was used. Growth was estimated from the daily increase in length $\left(\mathrm{mm} \mathrm{d}^{-1}\right)$ of each fish between release and recapture. This measure was chosen because it was more frequently recorded at capture than weight, and because length increased linearly between release and recapture and with respect to the number of days at liberty. The most appropriate model, after investigation of the variance structure using restricted maximum and maximum likelihood (REML/ML) methods (Fig. S2 in Supplement 1), was characterised as: Length increase $=$ Mean temperature during liberty $\times$ Ecosystem $\times$ Mean length between release and recapture. Supplement 1 provides full details of the model.

Environmental data. Temperature data were compiled from the International Council for the Exploration of the Sea (ICES) Oceanographic Database containing depth-specific conductivity-temperature-depth (CTD) and bottle measurements. To describe the hydrography of each ecosystem, we selected all available temperatures between 1950 and 2005 within the different areas under investigation (Table 1, and see Table S5 in Supplement 2 at www.int-res.com/articles/suppl/ m420p001_supp.pdf). Data were subsequently aggregated to obtain monthly means per year and $5 \mathrm{~m}$ depth stratum down to the maximum depth. To determine the thermal envelope potentially available to the tagged cod during the course of the study, concurrent ICES CTD data (i.e. those that matched as closely as possible the period during which the tags were collecting temperature data) were extracted from an area that enclosed the geographic limits of tag recaptures plus $0.5^{\circ}$ longitude or latitude in each compass direction (Table S4, and see Fig. S3 in Supplement 1). In some cases, the number of CTD casts in these areas was so low so that the period of extraction was broadened. As for the temperature data collated from the electronic tags, the pdf of available thermal conditions was calculated for each ecosystem on a monthly basis, and the monthly pdfs were averaged to provide a pdf of thermal experience for the full year or for the spawning season. Further details of the methods adopted for compiling the CTD data can be found in Supplement 1.

\section{RESULTS}

To date, a total of 902 cod have been recaptured. Many of the datasets recovered were short in duration so, to ensure that temperature data were collected from cod that had the opportunity to move and select preferred habitat, datasets shorter than $90 \mathrm{~d}$ in length were discarded. This left 384 records (Tables $1 \& \mathrm{~S} 2$ ), with a mean \pm SD time at liberty of $254 \pm 173 \mathrm{~d}$, of which 66 individuals were at liberty for $>1 \mathrm{yr}$ (see Fig. S1a in Supplement 1). The data comprise over 16 million records of both depth and temperature ( $>100000 \mathrm{~d}$ of data spread throughout the year; Table 1, Fig. S1b \& Table S2). Movement between release and recapture was evident in many individuals (Fig. 1, Table S2), although, with the exception of 1 individual that moved between the Baltic and the Kattegat, all of the cod were recaptured within the ecosystem where they were tagged.

Across all ecosystems and seasons, the daily temperature experience for individual cod ranged from sub-0 in northern ecosystems (lowest daily mean $=-1.33^{\circ} \mathrm{C}$, minimum observed value $=-1.54^{\circ} \mathrm{C}$; Table 1 ) to an upper limit of $19.39^{\circ} \mathrm{C}$ (highest daily mean; maximum observed value $=19.45^{\circ} \mathrm{C}$ ). In general, temperature experience was defined by the available environment. Thus in the relatively shallow, highly stratified waters in the Baltic and Skagerrak, cod regularly experienced daily temperature ranges of over $3^{\circ} \mathrm{C}$ as they moved between different water strata (Figs. 2a \& 3a). During summer, when stratification was greatest, individuals would change depth by only 10 or $20 \mathrm{~m}$ over $30 \mathrm{~min}$, but often experienced temperature changes greater than $2^{\circ} \mathrm{C}$ (Fig. 3b). Similarly, cod inhabiting deeper northern waters (Iceland, Barents Sea), experienced rapid temperature changes to temperatures as low as $-1^{\circ} \mathrm{C}$ (i.e. at the lower end of the thermal range) as they moved across thermal fronts (Figs. $2 b$ \& $3 b$ ). In contrast, in the less stratified southern North Sea (Fig. 2c), where cod 

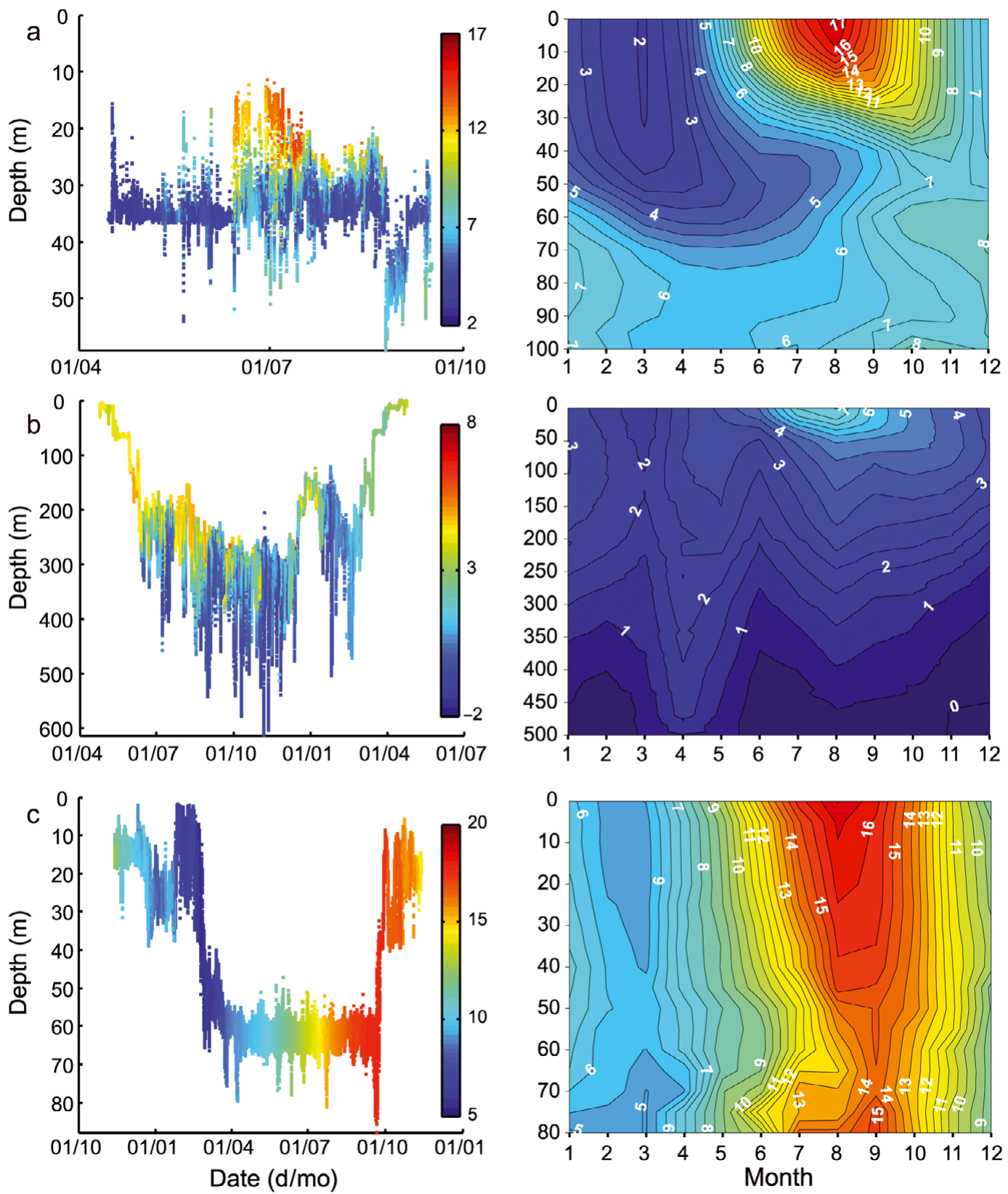

Fig. 2. Example time-series of depths and temperatures occupied by individual cod Gadus morhua (left), and the marine climate in the corresponding ecosystem (right): (a) the Baltic Sea; (b) north Iceland and (c) the southern North Sea. Each point on a timeseries chart shows the measured depth (10 min frequency), coloured to indicate water temperature $\left({ }^{\circ} \mathrm{C}\right)$. To illustrate clearly the range of temperatures experienced by each individual, colour scales are relative to each time series. Marine climate colour scales are consistent between panels to illustrate differences between ecosystems. Plots for all ecosystems studied can be found in Supplement 2 at www.int-res.com/articles/suppl/m420p001_supp.pdf

remained close to the seabed for much of the summer, temperature changes greater than $1^{\circ} \mathrm{C}$ over the course of a day were rarely observed (Fig. 3a). Instead, most cod experienced long periods at relatively high temperatures as the water column underwent seasonal warming (Fig. 2c, see Fig. S4 in Supplement 2).

Stocks in each ecosystem had an annual temperature experience that varied as expected with latitude; aver- age temperature experience increased as latitude decreased (Fig. 4a,b, Table 1). Within ecosystems, variation in annual temperature experience was also dependent upon the occupied depth; cod occupying deeper water experienced lower average temperatures (see Figs. S5 \& S6b in Supplement 2). Thus, cod in the southern North Sea and Baltic Sea were confined to relatively shallow water $(<100 \mathrm{~m})$ and experienced 

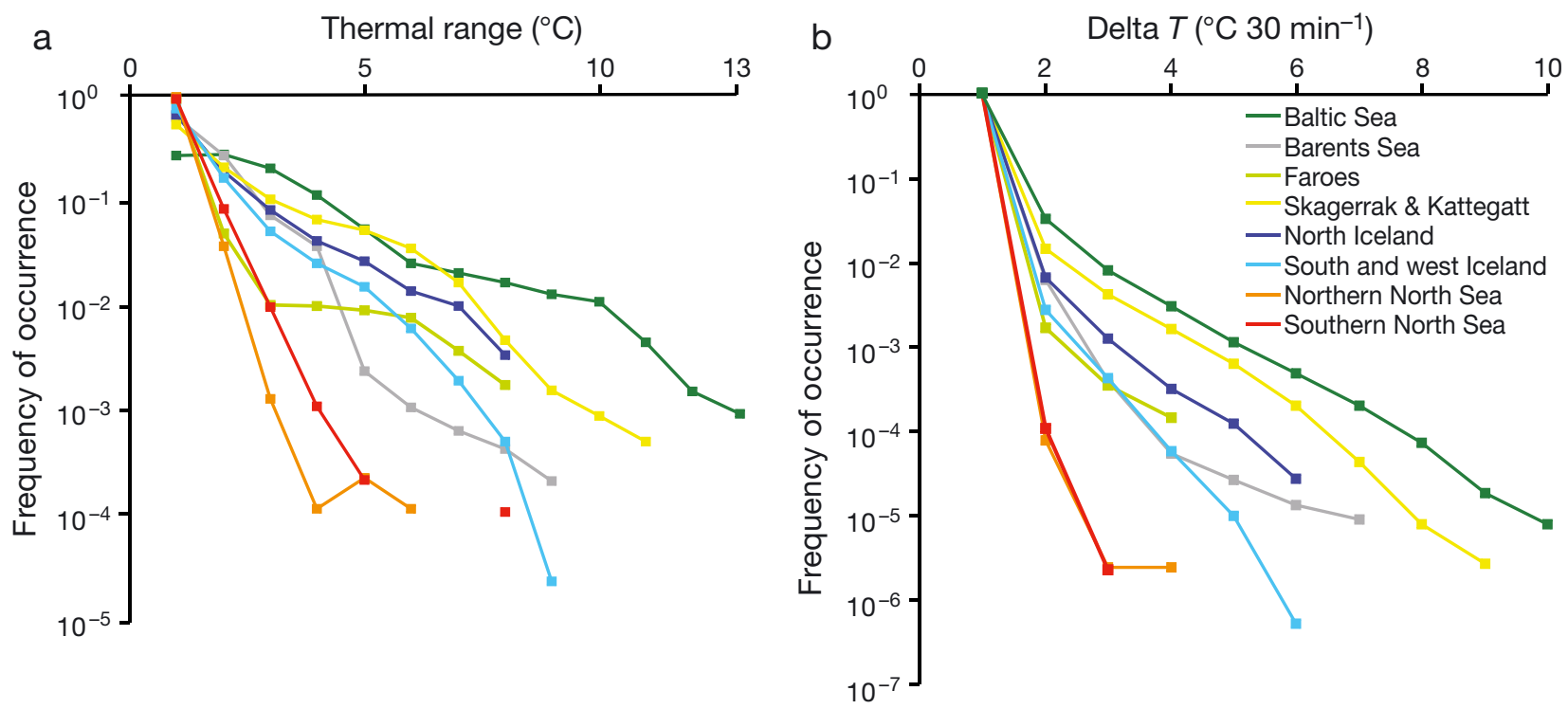

Fig. 3. Temporal changes in temperature experienced by Gadus morhua in the northeast Atlantic. (a) Observed frequencies of daily thermal range $\left(T^{\circ} \mathrm{C}_{\max }-T^{\circ} \mathrm{C}_{\min }\right)$ in each ecosystem; (b) observed frequencies of thermal shock $\left(\Delta T^{\circ} \mathrm{C} 30 \mathrm{~min}^{-1}\right)$ in each ecosystem. Frequencies of thermal shock were calculated for each region from datasets that had a temporal resolution of 30 min or greater ( $83 \%$ of total dataset: $81676 \mathrm{~d})$
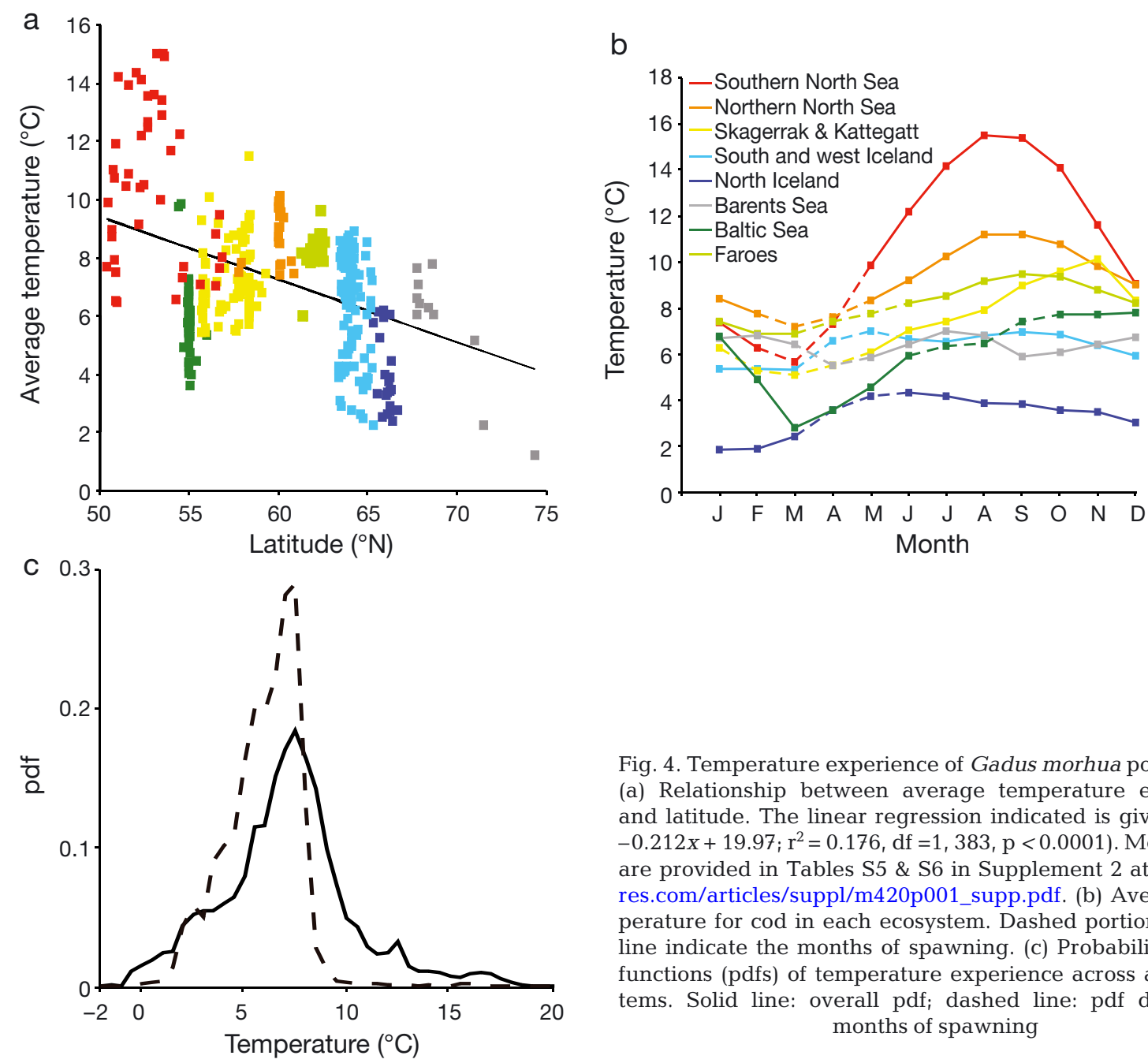

Fig. 4. Temperature experience of Gadus morhua populations. (a) Relationship between average temperature experience and latitude. The linear regression indicated is given by $y=$ $\left.-0.212 x+19.97 ; r^{2}=0.176, d f=1,383, p<0.0001\right)$. More details are provided in Tables S5 \& S6 in Supplement 2 at www.intres.com/articles/suppl/m420p001_supp.pdf. (b) Average temperature for cod in each ecosystem. Dashed portions of each line indicate the months of spawning. (c) Probability density functions (pdfs) of temperature experience across all ecosystems. Solid line: overall pdf; dashed line: pdf during the months of spawning 
broad temperature ranges over the course of a year that reflected their exposure to the seasonal change in water temperature (Fig. 4b, Table 1, Fig. S5). In the northern North Sea and Skagerrak, where some cod were able to move to water depths of up to $200 \mathrm{~m}$, overall temperature experience was narrower and was concentrated between 5 and $10^{\circ} \mathrm{C}$. In the deeper, northern ecosystems, where cod could access water as deep as $850 \mathrm{~m}$, average temperatures were cooler and narrower in range (Fig. 4a,b, Table 1). In consequence, the number of annual degree days that individual cod experienced ranged from 849 to 4353 (Table 1), and was greater at more southerly latitudes.

Overall growth rates of individuals in 6 regions were positively related to the temperatures experienced, and negatively related in the southern North Sea (Fig. 5) and north Iceland. Growth was significantly related to both average temperature experience and ecosystem occupied (Table 2). Taking only the highest growth rates into consideration, the relationship between temperature and growth was pyramidal. Thus, cod grew more rapidly up to temperatures around $10^{\circ} \mathrm{C}$, beyond which growth rates appeared to decrease again (Fig. 5). The growth of individuals was also significantly related to the number of degree days experienced, i.e. Growth in length $\left(\mathrm{cm} \mathrm{d}^{-1}\right)=0.002742$

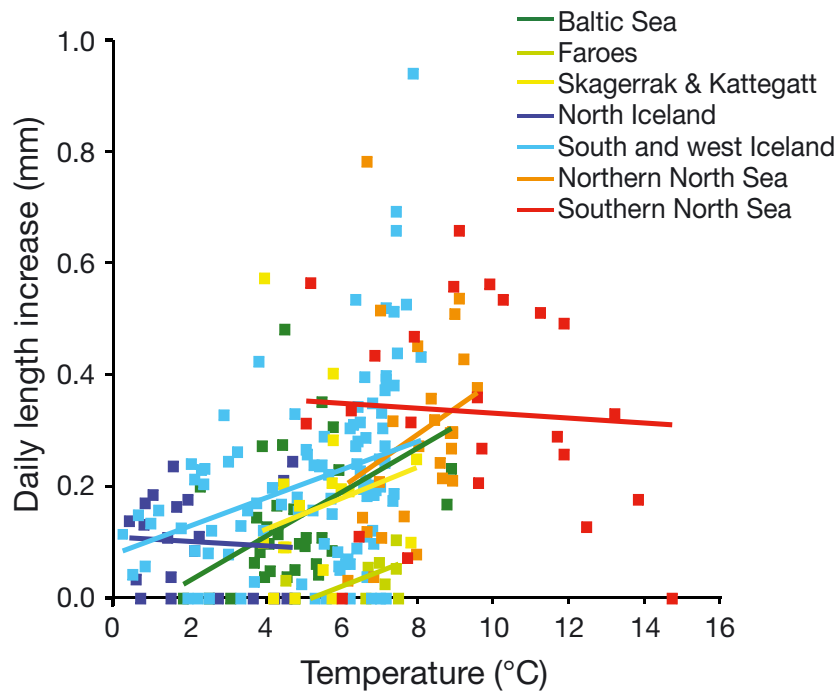

Fig. 5. Gadus morhua. Specific growth rate of individual cod in relation to temperature. Each point represents a single individual; lines indicate the relationship between temperature and growth rate for each ecosystem as determined by multiple regression analysis. Details of the regression model are provided in Supplement 2 at www.int-res.com/articles/ suppl/m420p001_supp.pdf. Lines indicate the best linear fit to the data from a generalised least squares regression model $\times$ Growing degree days $+0.8269, \mathrm{p}_{1,318}<0.01$. In the southern North Sea, where measured temperatures were the highest, the linear model may not have been entirely appropriate for analysing the growth relationship. In all other ecosystems, however, this assumption was reasonable, and so the linear model was retained.

The pdf of temperature experience for all cod observed in the study describes a peak at around $7^{\circ} \mathrm{C}$ (Fig. 4c), and upper and lower limits of -1 and $19^{\circ} \mathrm{C}$ respectively. The pdfs for cod in each ecosystem describe annual thermal ranges of between 9 and $15^{\circ} \mathrm{C}$ (Fig. 6, Table 1). Comparison of available temperature with occupied temperature, using the qualitative overlap index $\mathrm{O}$ (see 'Materials and methods') showed that temperatures below $5^{\circ} \mathrm{C}$ were occupied less than expected $(O \leq 1)$ in all but one of the ecosystems (the Skagerrak) where these conditions are available (Table 3a). In ecosystems with sub-zero conditions (Barents Sea, Faroes and Iceland), this was particularly marked $(\mathrm{O} \leq 0.5)$. Cod occupied temperatures above $10^{\circ} \mathrm{C}$ less than expected in the Baltic and north Iceland, but more than expected $(\mathrm{O} \geq 2)$ in the Barents Sea. During the spawning period, cod in all systems had a much narrower thermal experience than for the full year, generally between 5 and $10^{\circ} \mathrm{C}$. This range coincided with the thermal habitat available in the North Sea (both northern and southern), but in the Baltic, Faroes, Iceland and in the Barents Sea, cod did not occupy water temperatures below $5^{\circ} \mathrm{C}$ as much as expected, and water temperatures between 5 and $10^{\circ} \mathrm{C}$ more than expected (Table $3 b$ ).

\section{DISCUSSION}

Temperature is fundamental to the ecology and physiology of fish because it controls vital processes (Graham \& Harrod 2009). A multitude of studies have 

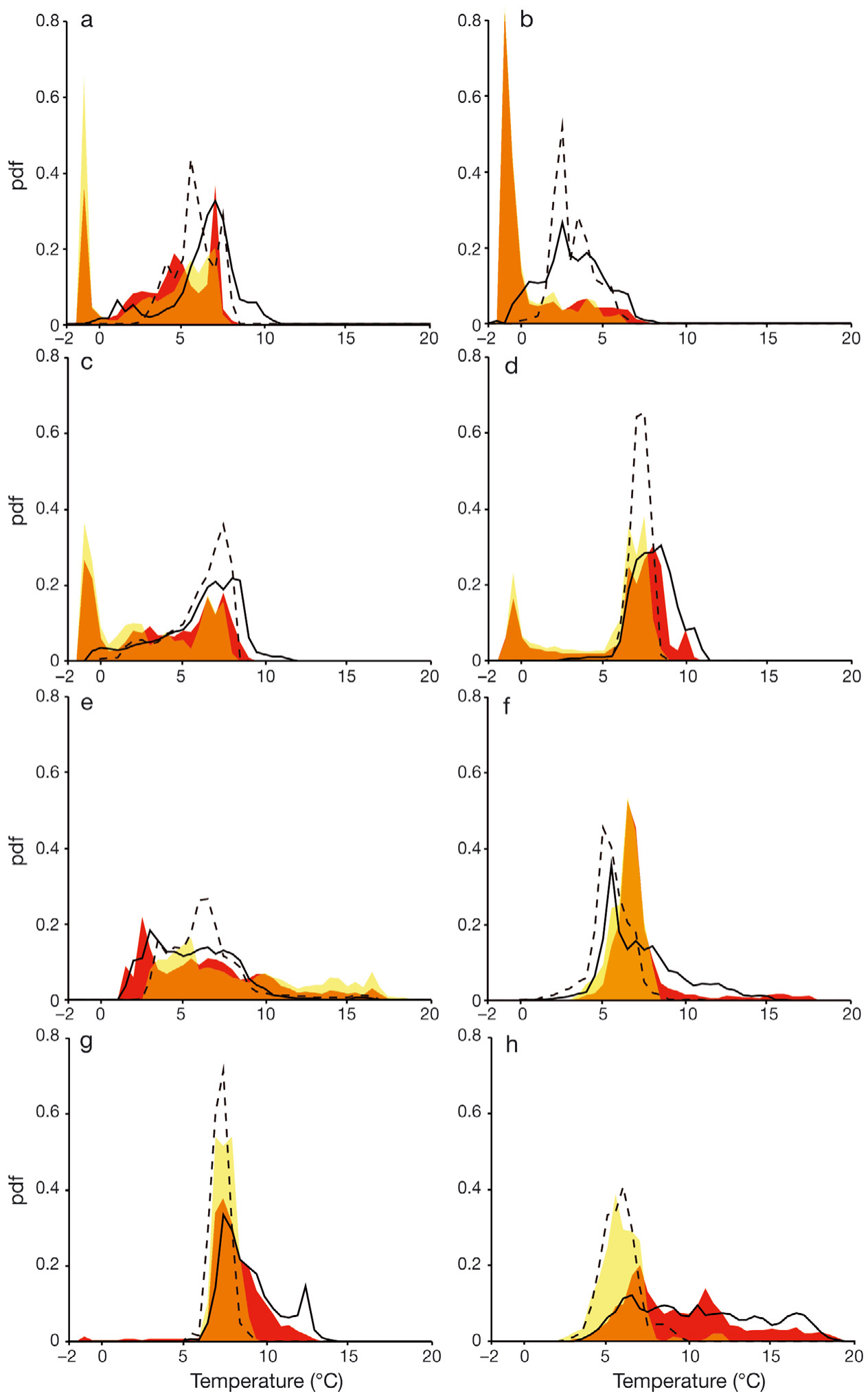

Fig. 6. Gadus morhua. Thermal habitat availability and thermal habitat occupation of cod in each ecosystem, represented as probability density functions (pdfs). Habitat availability is shown by the shaded areas, and habitat occupation by lines. The pdfs were calculated for the spawning season (yellow shading, dashed lines) and the full year (red shading, solid line). Orange shading shows where the habitat availability pdfs overlapped. (a) Barents Sea; (b) north Iceland; (c) southwest Iceland; (d) Faroes; (e) Baltic Sea; (f) Skagerrak; (g) northern North Sea; (h) southern North Sea 
demonstrated that cod are no exception (Jobling 1988, Brander 1995, Claireaux et al. 2000, Pörtner et al. 2001, Björnsson \& Steinarsson 2002, Lannig et al. 2004, Yoneda \& Wright 2005). Our study quantifies, for the first time, the natural temperature experience of individual cod across the latitudinal range of the species in relation to the available thermal niche.

\section{Broad thermal niche occupied by locally adapted stocks}

Our results show that cod occupy water from near freezing $\left(-1.5^{\circ} \mathrm{C}\right)$ to almost $20^{\circ} \mathrm{C}$ and that individuals endure medium-term (days to months) exposure to the upper and lower extremes. While this thermal range is not as wide as those reported for freshwater species such as goldfish Carassius auratus or brown bullhead Ictalurus nebulosus (Brett 1956), it is greater than the range reported for other ectothermic marine fishes such as blue marlin Makaira nigricans (Goodyear et al. 2008) and European plaice Platessa platessa (Hunter et al. 2004) and more in line with marine fish species that show some degree of endothermy such as salmon sharks Lamna ditropis (Weng et al. 2005) or bluefin tuna Thunnus thunnus (Block et al. 2005). This suggests that within each region, cod have the behavioural and physiological plasticity that allows them to occupy the full thermal extent of their ecosystem. However, while each population experienced and tolerated a wide range of oceanographic conditions, cod did not occupy habitat indiscriminately. For example, cod residing to the north of Iceland and in the Barents Sea experienced the coldest temperatures, but although the available thermal habitat was relatively restricted, cod were able to avoid long-term exposure to very cold temperatures. At more southerly latitudes, by contrast, cod occupied a much wider range of temperatures (North Sea) and occasionally experienced large fluctuations in daily temperature (Baltic Sea). Cod in the southern North Sea experienced the highest temperatures, with seasonal changes in water temperature leading to some cod remaining at $>16^{\circ} \mathrm{C}$ for many weeks to months.

In the shorter term, cod proved tolerant of relatively large daily temperature ranges, or were tolerant to rapid (30 min) changes in temperature. Again, different stocks had considerably different experiences. Cod of the north Iceland and Barents Sea stocks experienced temperatures as low as $-1.5^{\circ} \mathrm{C}$ when crossing the boundaries between water masses in deep polar fronts, but also experienced temperatures of up to $10^{\circ} \mathrm{C}$ when moving inshore at spawning time. In both areas, cod tolerated cold shocks of up to $6^{\circ} \mathrm{C}$ as they moved vertically across the boundaries between water masses. Such shocks were also experienced by cod in the Baltic Sea and Skagerrak and, in extreme cases, led to some cod experiencing daily thermal ranges greater than $10^{\circ} \mathrm{C}$ and up to $13^{\circ} \mathrm{C}$, which is similar to or greater than the temperature ranges reported for deep-diving oceanic predators (Block et al. 2005). These events were most likely linked to foraging activity, since cod did not appear to avoid re-exposure to the shocks (Figs. $2 \& 3$ ) and, indeed, continued to move across thermal boundaries for periods of many weeks and months. The evidence of the frequency and magnitude of thermal shocks in wild fish is extremely limited (Donaldson et al. 2008), and these data suggest it may be an important factor in understanding the physiological adaptations of large, mobile fish species. Such tolerance of a wide range of thermal conditions is likely to have a genetic basis: different stocks of cod are known to have polymorphisms in haemoglobin type (Nielsen et al. 2003,

Table 3. Gadus morhua. Overlap between available thermal habitat and thermal habitat occupied by cod (a) throughout the year and (b) during the spawning season. Bold values: thermal envelopes that were under-represented in the dataset (less than half the frequency expected on basis of random distribution); shaded values: thermal envelopes that were over-represented in the dataset (more than twice the frequency expected by chance). -: a comparison could not be made as the tag experience data did not extend to this temperature category. id: insufficient data

\begin{tabular}{|c|c|c|c|c|c|c|c|c|}
\hline Temperature $\left({ }^{\circ} \mathrm{C}\right)$ & Baltic & Barents & Faroes & N Iceland & SW Iceland & N North Sea & S North Sea & Skagerrak \\
\hline \multicolumn{9}{|l|}{ (a) Overall } \\
\hline$<5$ & 1.219 & 0.382 & 0.986 & id & 0.928 & 0.550 & 0.156 & 2.154 \\
\hline 5 to 10 & 1.322 & 1.588 & 0.901 & 0.978 & 1.611 & 1.450 & 1.100 & 0.907 \\
\hline 10 to 15 & 0.189 & 3.187 & 1.032 & 1.169 & 0.037 & 1.104 & 1.453 & 1.810 \\
\hline 15 to 20 & 0.0732 & id & 1.277 & id & - & - & - & 0.08 \\
\hline \multicolumn{9}{|l|}{ (b) Spawning time } \\
\hline$<5$ & 1.705 & 0.479 & 1.031 & - & 0.944 & 0.360 & 0.014 & 2.165 \\
\hline 5 to 10 & 2.086 & 1.569 & 1.012 & 1.000 & 2.252 & 2.185 & 1.198 & 0.805 \\
\hline 10 to 15 & 0.151 & - & id & - & - & - & - & - \\
\hline 15 to 20 & 0.0732 & - & - & - & - & - & - & - \\
\hline
\end{tabular}


Petersen \& Steffensen 2003) that confer advantage in different environments, and recent evidence has suggested that some genes influence behaviour and ecological performance in highly stratified environments (e.g. PanI allele: Case et al. 2005, Sarvas \& Fevolden 2005, Pampoulie et al. 2008).

\section{Defining the thermal niche for cod- growth and feeding}

Optimal temperatures for cod have been described a number of times, cover a range between 7 and $15^{\circ} \mathrm{C}$, and depend on the criteria or 'currency' used to assess optimality (e.g. growth, metabolic scope). However, our results show that cod often resided at temperatures that would not be considered optimal for growth, and did not appear to behave in a way as to move closer (vertically or geographically) to described thermal optima. These results suggest that the temperature range that leads to high growth rates may be much wider than assumed from laboratory studies. Indeed, our data suggest that within their thermal niche, the growth rates of cod increase with temperature, either when considering the thermal range within each region, or across the regions we studied, even in the warmest region (southern North Sea; specific growth rate $=0.053 \mathrm{~cm} \mathrm{~cm}^{-1} \mathrm{~d}^{-1}$ ), although there was some evidence for a downturn beyond mean thermal experience of $16^{\circ} \mathrm{C}$. These individual-based growth estimates concur with Brander's (1995) population-based estimates that cod weight-at-age is greater in warmer environments, with the fastest-growing cod found at the southern- and western-most limits of their distribution (the Celtic Sea). The data are also direct and detailed evidence in support of the growing degree day (GDD) metric (Neuheimer \& Taggart 2007).

Our data also show that, in addition to the general trend for increased growth rate at higher average temperatures, the growth rates of cod from different ecosystems overlapped, indicating that there are factors independent of temperature that also had an effect on growth. For example, cod in the southern North Sea, considered to be a very productive and food-rich ecosystem, had the highest growth rates of all despite experiencing temperatures that have been shown to be very stressful in laboratory experiments (Lannig et al. 2004). In contrast, cod at what would be conventionally described as being at 'optimal' temperatures, such as those living on the Faroe Plateau, exhibited very low growth rates during our study, particularly when compared to cod in southwest Iceland, which grew faster at similar temperatures. This may be attributed to the very low productivity in the region during the study period (Steingrund \& Gaard 2005). Furthermore, the generally slower growth of cod in the colder, northern ecosystems may be accounted for, in part, by the larger biomass of the stocks and greater competition that individuals face for food relative to the depleted stocks in the southern ecosystems (Michalsen et al. 1998, Sundby \& Nakken 2008), or because standard metabolic rates of northern cod are higher than their southern counterparts (Sylvestre et al. 2007).

Overall, our data and analysis show that it is necessary to take into account a number of factors when considering behavioural or biological outcomes. The identification of a single thermal optimum is unlikely to apply to an entire metapopulation, nor is a thermal optimum likely to drive behaviour at all times and in all locations. This is probably why cod that experienced temperatures that might be considered suboptimal for growth (e.g. those in northern Iceland that occupied cold water and that regularly experienced changes in temperature of $>4^{\circ} \mathrm{C}$ ) did not move into conventionally more 'favourable' thermal conditions. This underlines the need to adopt a multivariate approach to analyses of growth rate. Thus, when considering how productivity or distribution of stocks might change in the future, it may be more appropriate to consider the constraints or limits to habitat occupation rather than attempt to identify preferences.

\section{Defining the thermal niche for $\operatorname{cod}-$ maturation and spawning}

During the spawning season, the thermal experience of cod in each stock was narrower, less variable and matched more closely the 'optimal' range for growth. In consequence, the mean temperature during spawning time was very similar across stocks. This phenomenon was not just because the environmental temperature range also narrows in each ecosystem during the spawning season; cod in the deeper, cooler ecosystems moved into shallower, warmer water. In the Baltic, cod moved into deeper, cooler water. As a result, cod in these systems occupied temperatures between 5 and $10^{\circ} \mathrm{C}$ more than expected, or they occupied temperatures below $5^{\circ} \mathrm{C}$ less than expected. This suggests that the thermal requirements of cod may be particularly critical at spawning time, perhaps because of the role temperature plays in gonad maturation (Yoneda \& Wright 2005, Kjesbu et al. 2010), the development rates of fertilised eggs (Geffen et al. 2006), or indirectly via its effects on the larval food availability (O'Brien et al. 2000, Ottersen \& Loeng 2000, Beaugrand et al. 2003, Drinkwater 2005). The avoidance of warm water in the spawning season in the Baltic and of colder water in Icelandic/Barents Sea waters may even underlie spawning migrations that are so characteristic of these stocks. 


\section{Cod populations and marine climate}

Historically, cod has been the dominant demersal species in temperate and boreal ecosystems and the foundation of a huge fishing industry (Cook et al. 1997, O'Brien et al. 2000, Christensen et al. 2003, Hutchings 2004, Rose 2004). The ecological success of cod, and its wide distribution between $\sim 40$ and $70^{\circ} \mathrm{N}$, was likely to have been founded on wide environmental tolerance, behavioural flexibility and local adaptation. Our results underline that, rather than being limited by a narrow range of optimal temperatures, cod are extremely well adapted to survive and grow under exposure to a wide range of water temperatures, be they well below the described optimal temperature for growth, or well above it. Furthermore, cod are able to tolerate relatively large and rapid changes in temperature as a consequence of moving between different water strata in search of food. Thus, cod are clearly able to occupy thermally 'sub- or super-optimal' habitats, and may even thrive in them provided that food resources are adequate (Brander 1995).

Recent studies have suggested that the range of cod in the NE Atlantic will contract as mean water temperatures increase as a consequence of climate change (Blanchard et al. 2005, Drinkwater 2005). Evidence from some recent studies has supported claims that the southern limit to distribution has already moved northwards as ocean warming increases (Perry et al. 2005, Rindorf \& Lewy 2006, Dulvy et al. 2008). Warming seas may affect cod distribution and productivity by exceeding physiological tolerance in the southern range and adversely affecting recruitment through changes in the abundance and distribution of planktonic prey for larval and juvenile cod (O'Brien et al. 2000, Beaugrand et al. 2003). This contraction may also be mediated through changes in the distribution of important prey species (Dulvy et al. 2008). The evidence that identifies the mechanism(s) responsible for the changes already observed is equivocal, however. Our results suggest that the stock of adult cod in the NE Atlantic is able to occupy a broad range of habitats and that each sub-stock we studied occupied almost the full range of thermal habitat available to it. We cannot determine from our data if northward migration or substitution of sub-stocks will occur if water temperatures rise, or if the most southern sub-stock will be able to tolerate the change in marine climate predicted for the next century. However, our data suggest that predictions of response to marine climate change need to take into account the limits to habitat occupation, and not just focus on the optima for growth. As such, cod stocks appear to have the potential to cope with the increases in sea temperature predicted for the next century or more. This assertion is supported by a recent study of prehistoric fish communities which shows that cod was a dominant part of the ecosystem in Danish waters, despite seawater temperatures $2^{\circ} \mathrm{C}$ higher than at present (Enghoff et al. 2007).

Conversely, our results also show that it is possible to identify potential tipping points at which climate change may exert a particularly strong effect. Although adult cod could occupy most temperatures during the feeding season, the range of temperatures at which spawning took place was much narrower and peaked at $7^{\circ} \mathrm{C}$. Future changes in sea temperature, especially those at spawning time, may lead to spatial or temporal adjustment of spawning. The consequences of rapid changes in the location or timing of spawning are difficult to predict, but would probably lead to changes in the spatial distribution and survivorship of larvae with subsequent effects on the distribution of the adult stock. Thus, while cod in the past have occupied a wide range of environments across the northern hemisphere, they may not be able to respond to rapid climate change in the future. Any further threats to successful recruitment (e.g. through failure of spawning) increase the risk of population collapse, especially at low stock sizes (Brander 2005). Reduced fishing mortality therefore remains the best chance of achieving stock recovery.

\section{LITERATURE CITED}

Beaugrand G, Brander KM, Lindley JA, Souissi S, Reid PC (2003) Plankton effect on cod recruitment in the North Sea. Nature 426:661-664

Björnsson B, Steinarsson A (2002) The food-unlimited growth rate of Atlantic cod (Gadus morhua). Can J Fish Aquat Sci 59:494-502

Blanchard JL, Mills C, Jennings S, Fox CJ, Rackham BD, Eastwood PD, O'Brien CM (2005) Distribution-abundance relationships for North Sea Atlantic cod (Gadus morhua): observation versus theory. Can J Fish Aquat Sci 62: 2001-2009

> Block BA, Teo SLH, Walli A, Boustany A and others (2005) Electronic tagging and population structure of Atlantic bluefin tuna. Nature 434:1121-1127

Boutilier RG (1998) Physiological ecology in cold ocean fisheries: a case study in Atlantic cod. In: Pörtner HO, Playle RC (eds) Cold ocean physiology. Cambridge University Press, Cambridge, p 463-469

Brander KM (1995) The effect of temperature on growth of Atlantic cod (Gadus morhua L.). ICES J Mar Sci 52:1-10

> Brander KM (2005) Cod recruitment is strongly affected by climate when stock biomass is low. ICES J Mar Sci 62: 339-343

Brett JR (1956) Some principles in the thermal requirements of fishes. Q Rev Biol 31:75-87

Brown JH, Gilooly JF, Allen AP, Savage VM, West GB (2004) Towards a metabolic theory of ecology. Ecology 85: 1771-1789

- Case RAJ, Hutchinson WF, Hauser L, Van Oosterhout C, Carvalho GR (2005) Macro- and micro-geographic variation in pantophysin (PanI) allele frequencies in NE Atlantic cod 
Gadus morhua. Mar Ecol Prog Ser 301:267-278

Christensen V, Guenette S, Heymans JJ, Walters CJ, Watson R, Zeller D, Pauly D (2003) Hundred-year decline of North Atlantic predatory fishes. Fish Fish 4:1-24

- Claireaux G, Webber DM, Kerr SR, Boutilier RG (1995) Physiology and behaviour of free-swimming Atlantic cod (Gadus morhua) facing fluctuating temperature conditions. J Exp Biol 198:49-60

Claireaux G, Webber DM, Lagardère JP, Kerr SR (2000) Influence of water temperature and oxygenation on the aerobic metabolic scope of Atlantic cod (Gadus morhua). J Sea Res 44:257-265

Cook RM, Sinclair A, Stefansson G (1997) Potential collapse of North Sea cod stocks. Nature 385:521-522

Cooke SJ, O'Connor CM (2010) Making conservation physiology relevant to policy makers and conservation practitioners. Conserv Lett 3:159-166

Donaldson MR, Cooke SJ, Patterson DA, Macdonald JS (2008) Cold shock and fish. J Fish Biol 73:1491-1530

> Drinkwater K (2005) The response of Atlantic cod to future climate change. ICES J Mar Sci 62:1327-1337

Dulvy NK, Rogers SI, Jennings S, Stelzenmüller V, Dye SR, Skjoldal HR (2008) Climate change and deepening of the North Sea fish assemblage: a biotic indicator of warming seas. J Appl Ecol 45:1029-1039

Enghoff IB, MacKenzie BR, Nielsen E (2007) The Danish fish fauna during the warm Atlantic period (ca. 7000-3900 $\mathrm{BC}$ ): forerunner of future changes? Fish Res 87:167-180

Geffen A, Fox CJ, Nash RDM (2006) Temperature-dependent development rates of cod Gadus morhua eggs. J Fish Biol 69:1060-1080

> Goodyear CP, Luo J, Prince ED, Hoolihan JP, Snodgrass D, Orbesen ES, Serafy JE (2008) Vertical habitat use of Atlantic blue marlin Makaira nigricans: interaction with pelagic longline gear. Mar Ecol Prog Ser 365:233-245

Graham CT, Harrod C (2009) Climate change and the fish of Britain and Ireland - a review. J Fish Biol 74:1143-1205

Hunter E, Metcalfe JD, Arnold GP, Reynolds JD (2004) Impacts of migratory behaviour on population structure in North Sea plaice. J Anim Ecol 73:377-385

$>$ Hutchings JA (2004) The cod that got away. Nature 428: 899-900

- Hutchings J, Myers R (1994) What can be learned from the collapse of a renewable resource? Atlantic cod, Gadus morhua, of Newfoundland and Labrador. Can J Fish Aquat Sci 51:2126-2146

ICES (International Council for the Exploration of the Sea) (2007) Report of the ICES Advisory Committee on Fishery Management, Advisory Committee on the Marine Environment and Advisory Committee on Ecosystems. ICES Advice Book 1. Introduction, overviews and special requests. ICES, Copenhagen

Jobling M (1988) A review of the physiological and nutritional energetics of cod, Gadus morhua L., with particular reference to growth under farmed conditions. Aquaculture 70: $1-19$

Kjesbu OS, Righton D, Kruger-Johnson M, Thorsen A, Michalsen K, Fonn M, Witthames PW (2010) Thermal dynamics of ovarian maturation in Atlantic cod (Gadus morhua). Can J Fish Aquat Sci 67:605-625

Lannig G, Bock C, Sartorius FJ, Pörtner HO (2004) Oxygen limitation of thermal tolerance in cod, Gadus morhua L., studied by magnetic resonance imaging and on-line venous oxygen monitoring. Am J Physiol 287:902-910

Michalsen K, Ottersen G, Nakken O (1998) Growth of northeast Arctic cod (Gadus morhua L.) in relation to ambient temperature. ICES J Mar Sci 55:863-877
Neat F, Righton D (2007) Warm water occupancy by North Sea cod. Proc Biol Sci 274:789-798

Neuheimer AB, Taggart CT (2007) The growing degree day and fish size-at-age: the overlooked metric. Can J Fish Aquat Sci 64:375-385

Nielsen EE, Hansen MM, Ruzzante DE, Meldrup D, Grønkjær P (2003) Evidence of a hybrid-zone in Atlantic cod (Gadus morhua) in the Baltic and the Danish Belt Sea revealed by individual admixture analysis. Mol Ecol 12:1497-1508

O'Brien CMC, Fox J, Planque B, Casey J (2000) Climate variability and North Sea cod. Nature 404:142

> Ottersen G, Loeng H (2000) Covariability in early growth and year-class strength of Barents Sea cod, haddock and herring: the environmental link. ICES J Mar Sci 57:339-348

Pálsson OK, Thorsteinsson V (2003) Migration patterns, ambient temperature, and growth of Icelandic cod (Gadus morhua): evidence from storage tag data. Can J Fish Aquat Sci 60:1409-1423

Pampoulie C, Jakobsdóttir KB, Marteinsdóttir G, Thorsteinsson V (2008) Are vertical behaviour patterns related to the pantophysin locus in the Atlantic cod (Gadus morhua L.). Behav Genet 38:76-81

> Parmesan C (2006) Ecological and evolutionary responses to recent climate change. Annu Rev Ecol Evol Syst 37: $637-669$

Perry AL, Lowe PJ, Ellis JR, Reynolds JD (2005) Climate change and distribution shifts in marine fishes. Science 308:1912-1915

> Petersen MF, Steffensen JF (2003) Preferred temperature of juvenile Atlantic cod Gadus morhua with different haemoglobin genotypes at normoxia and moderate hypoxia. J Exp Biol 206:359-364

Pitcher T, Kalikoski D, Pramod G, Short K (2009) Not honouring the code. Nature 457:658-659

Pörtner HO, Knust R (2007) Climate change affects marine fishes through the oxygen limitation of thermal tolerance. Science 315:95-97

Pörtner HO, Berdal B, Blust R, Brix O and others (2001) Climate induced temperature effects on growth performance, fecundity and recruitment in marine fish: developing a hypothesis for cause and effect relationships in Atlantic cod (Gadus morhua) and common eelpout (Zoarces viviparus). Cont Shelf Res 21:1975-1997

Rice JC (2006) Every which way but up: the sad story of Atlantic groundfish, featuring Northern cod and North Sea cod. Bull Mar Sci 78:429-465

Rindorf A, Lewy P (2006) Warm, windy winters drive cod north and homing of spawners keeps them there. J Appl Ecol 43:445-453

Ropert-Coudert Y, Wilson RP (2005) Trends and perspectives in animal-attached remote sensing. Front Ecol Environ 3: 437-444

Rose GA (2004) Reconciling overfishing and climate change with stock dynamics of Atlantic cod (Gadus morhua) over 500 years. Can J Fish Aquat Sci 61:1553-1557

> Sarvas TH, Fevolden SE (2005) The ScnDNA locus PanI reveals concurrent presence of different populations of Atlantic cod (Gadus morhua L.) within a single fjord. Fish Res 76:307-316

Schurmann H, Steffensen JF (1992) Lethal oxygen levels at different temperature and the preferred temperature during hypoxia on the Atlantic cod, Gadus morhua. J Fish Biol 41:927-934

> Steingrund P, Gaard E (2005) Relationship between phytoplankton production and cod production on the Faroe shelf. ICES J Mar Sci 62:163-176

Sundby S, Nakken O (2008) Spatial shifts in spawning habi- 
tats of Arcto-Norwegian cod related to multidecadal climate oscillations and climate change. ICES J Mar Sci 65:953-962

Svedäng H, Righton D, Jonsson P (2007) Migratory behaviour of Atlantic cod Gadus morhua: natal homing is the prime stock-separating mechanism. Mar Ecol Prog Ser 345:1-12

Sylvestre EL, Lapointe D, Dutil JD, Guderley H (2007) Thermal sensitivity of metabolic rates and swimming performance in two latitudinally separated populations of cod, Gadus morhua L. J Comp Physiol B 177:447-460

Weng KC, Castilho PC, Morrissette JM, Landeira-Fernandez AM, Holts DB, Schallert RJ, Goldman KJ, Block BA (2005) Satellite tagging and cardiac physiology reveal niche expansion in salmon sharks. Science 310:104-106

Wieland K, Jarre-Teichmann A, Horbowa K (2000) Changes

Editorial responsibility: Hans Heinrich Janssen,

Oldendorf/Luhe, Germany in the timing of spawning of Baltic cod: possible causes and implications for recruitment. ICES J Mar Sci 57:452-464

Wikelski M, Cook SJ (2006) Conservation physiology. Trends Ecol Evol 21:38-46

Worm B, Barbier EB, Beaumont N, Duffy JE and others (2006) Impacts of biodiversity loss on ocean ecosystem services. Science 314:787-790

Yoneda M, Wright PJ (2005) Effects of varying temperature and food availability on growth and reproduction in first-time spawning female Atlantic cod. J Fish Biol 67: 1225-1241

Young JL, Bornik ZB, Marcotte ML, Charlie KN, Wagner GN, Hinch SG, Cooke SJ (2006) Integrating physiology and life history to improve fisheries management and conservation. Fish Fish 7:262-283

Submitted: May 10, 2010; Accepted: October 21, 2010

Proofs received from author(s): December 10, 2010 